\title{
Comparative study of two different treatment regimes for management of myiasis in Bovines
}

\author{
P.V.PATIL
}

\begin{abstract}
Therapeutic effects of two different treatment regimes on the healing of myiasis wound in bovines were evaluated in the present study. The study was conducted in 10 myiasis affected bovines at Cattle Breeding farm, College of Veterinary and Animal sciences, Udgir, Dist. Latur (Maharashtra). The best result was obtained in treatment group B where the wounds were treated with Inj. Ivermectin and Topicure spray than treatment group A where the wounds were treated with Turpentine oil locally and parental administration of streptopenicillin. It was observed that in treatment group B maggots are disappeared within 48 hours and oozing of blood containing fluid was stopped after second day after treatment with Inj. Ivermectin and complete healing of wound was taken place within 8 to 9 days after treatment whereas in treatment group A it was observed that after $4^{\text {th }}$ day of treatment, oozing of maggots and bloody fluid from wound was reduced day by day and complete healing of wound was taken place on $15^{\text {th }}$ day after treatment. Topicure is herbal spray having wide spectrum of activities to treat skin disorders of varied etiology and has better spreadability and deeper penetration into lesions. Also Topicure spray effectively kills the maggots and prevents further re-infestation. The present study suggests that, treatment of myiasis wound with subcutaneous administration of inj.ivermectin single dose and spraying of Topicure spray locally was the most effective and may be practiced for the clinical management of myiasis in bovines.
\end{abstract}

KEY WORDS : Myiasis wound, Healing, Inj.ivermectin

How to CITE THIS PAPER : Patil, P.V. (2014). Comparative study of two different treatment regimes for management of myiasis in Bovines. Res. J. Animal Hus. \& Dairy Sci., 5(2) : 148-150. 